DOI: 10.20472/IAC.2018.001.015

\title{
DUANGSAMORN RUNGSAWANPHO
}

Suan Sunandha Rajabhat University, Thailand

\section{INFLUENCE OF CORPORATE CULTURE ON THE EMPLOYEES' WORK PERFORMANCE OF ELDERCARE SERVICE BUSINESS}

\begin{abstract}
:
The purposes of this research were to: 1) investigate the attitude level of employee towards the corporate culture on eldercare service business; and 2) examine the influence of the corporate culture on work performance of the employees of eldercare service business. This study utilized a quantitative research approach. The research sample consisted of 400 employees of eldercare service business in Bangkok and metropolitan. The sample was obtained by systematic sampling. The study was carried out between April and June, 2018. The research instrument was a questionnaire. Data were analyzed by descriptive statistics including mean, and standard deviation and a structural equation model. The result of this research showed that: 1) the overall attitudes of employee towards the corporate culture on eldercare service business were rated at a high level, and when considering each dimension of their attitudes including the attitudes on long term orientation was found to have the highest mean score, followed by protection of their own right, participation as a group member, and performance orientation, each of which was rated at a high level. In terms of employees' overall work performance, it was also rated at a high level, and when considering each dimension, organizational loyalty had the highest mean score, followed by willingness for cooperation and efficiency in work performance respectively.; and 2) the corporate culture had a direct influence on the employees' work performance with a .05 level of statistical significance. This research can be used as a guideline for the elderly care service business to determine the appropriate organizational culture for long-term loyalty to the employees.
\end{abstract}

\section{Keywords:}

Corporate culture, Employees' Work Performance, Eldercare Service Business

JEL Classification: Y80 


\section{Introduction}

Corporate culture is a key to success that can create sustainable competitive advantage for the organization. It reflects the values, beliefs, and behavior patterns that are accepted and practiced by the members of the organization. It also determines behaviors in working for personnel of the organization. Creative corporate culture can bring all members of the organization together and makes them proud, confident to think and do things, love and bond to the organization. It also creates an awareness of being a part of the organization that makes the members to do their best for the success of themselves, their groups or departments, and the organization. Moreover, it also enables people to be reasonable to exercise accepted behaviors (Sanguanwongwan, 2003).

Affective commitment to the organization is one of the characteristics that the organization requires from its members. Such characteristic leads the members to be willing and dedicated to work for the organization. It also enables them to agree and adhere to the goals and visions of the organization which in turn leads them to work hard with their best performance so that such goals and visions can be achieved. It also leads the members to be happy to continue working for the organization. Affective commitment to the organization can also lessen employees' intention to resign from work as well as reduce stress gained from work. This can create good working environment which in turn makes the employees or the members happy and willing to cooperate in any tasks and it also makes the organization become a reliable organization in the view of outsiders (Gubman, 2003).

The eldercare service business in Thailand has been increasingly expanding recently. This is because Thailand has become an aging society which is a result of a decrease in birth rate, together with a fact that people tend to have longer life from advances in medical technology and better care given to senior people in the country. Nowadays, the number of senior people has been increasing. The expansion of the eldercare service business is also a result of the current situation of the Thai society in which culture of living together in a big family has been transformed into a small family. Moreover, it is also a result of changing economic situation in which people of working age need to work outside their houses and have to leave senior family members at home. It shows that at the present time, family has less important role in taking care of physical and mental health of senior people. Therefore, these senior people, who may live alone or live separately from other family members, need other people or organizations to provide proper care for them so that they will not be a burden for the society (Thammasane, 2012).

The expansion of the eldercare service business, as a result of the situations mentioned earlier, requires entrepreneurs of the business to hire more employees so that they can provide better service for the senior people. when employing many employees, the business has to pay a special attention to bring these employees 
together and make them feel that they are parts of the organization and need to work in the same direction. To do this, corporate culture should be used as a main mechanism. Upon realizing the significance of the corporate culture in the eldercare service business, the researcher was interested to study the influence of the corporate culture on the performance of the employees in the eldercare service business. Specifically, this study looked at the level of opinion on the role of corporate culture and the performance of the employees. The results were expected to be used as guidelines for planning and developing an efficient working model that could create team work and good cooperation among employees. They were also expected to provide valuable information for the development of culture for working within the organization that could create a strong affective commitment among the employees.

\section{Research Objectives}

This research aimed to:

1) investigate the level of corporate culture on eldercare service business; and

2) examine the influence of the corporate culture on work performance of the employees of eldercare service business.

\section{Research Methodology}

This research employed a quantitative research methodology. The sample consisted of 400 employees of the eldercare service business. They were selected via systematic sampling. The study was conducted between April and Jun 2018. Data were collected with the mean of a questionnaire. The main content of the questionnaire involved questions or opinions on corporate culture and performance of the employees of the eldercare service business which were developed in a form of five-level Likert scale.

The research paid a special attention on the test of the questionnaire's content validity so that it was sent to three experts for verifying. After that, it was improved until the index of item objective congruence was higher than 0.6 in every item. In addition, the questionnaire was also tested for its reliability. In doing it, thirty copies of the questionnaire were tested with respondents to find out the Cronbach's Alpha value. The result showed that the Cronbach's Alpha values of the corporate culture and the performance of the employees were at .887 and.954 respectively. After that, the researcher used the improved version of the questionnaire to collect the data from 400 respondents. The collected data were then analyzed with descriptive 
statistics including mean and standard deviation, as well as a structural equation model.

\section{Research Results}

The data analysis showed that:

(1) The overall opinion on the corporate culture in the aspect of long term orientation was rated at a high level. This dimension of the corporate culture included, sorted in a descending order, the organization focusing more on long-term planning for the future than on solving current problems $(\bar{x}=3.84)$, the organization emphasizing on having a clear plan for the future $(\bar{x}=3.83)$, the organization having a plan for the future operation $(\bar{x}=3.78)$, the organization determining goals for a future plan on an ongoing basis $(\bar{x}=3.57)$, and the organization dedicating to achieve the determined plan $(\bar{x}=3.53)$.

(2) The overall opinion on the corporate culture in the aspect of protection of its own right was rated at a high level. This dimension of corporate culture included, sorted in a descending order, all employees being able to express and exchange their opinion with others, $(\bar{x}=3.81)$, all employees having a right to offer different opinion or behave differently from other employees which may be different from other employees $(\bar{x}=3.80)$, all employees having an equal right to use resources of the organization $(\bar{x}$ $=3.69)$, all employees exercising their right to behave equally $(\bar{x}=3.58)$, and all employees always respecting their own right as well as the right of others $(\bar{x}=3.49)$.

(3) The overall opinion on the corporate culture in the aspect of participation as a group member was rated at a high level. This dimension of the corporate culture included, sorted in a descending order, all employees always respecting a decision made by a group $(\bar{x}=3.70)$, all employees giving an importance to harmony within a group $(\bar{x}=3.68)$, all employees being encouraged to work as a team rather than to work individually $(\bar{x}=3.62$ ), all employees being willing and ready to work for a group/an organization even though they have to sacrifice their own benefits $(\bar{x}=3.60)$, and all employees being proud of the success of members of a group $(\bar{x}=3.60)$.

(4) The overall opinion on the corporate culture in the aspect of performance orientation was rated at a high level. This dimension of the corporate culture included, sorted in a descending order, the organization encouraging the employees to acquire new knowledge to enhance their performance $(\bar{x}=3.75)$, the organization encouraging working for high efficiency on an on-going basis $(\bar{x}=3.66)$, the organization supporting the use of innovation to improve work performance $(\bar{x}=3.59)$, the organization evaluating employees from their performance efficiently $(\bar{x}=3.54)$, and the organization informing all employees about the due date for every task $(\bar{x}=3.53)$. 
(5) The overall performance of the employees in terms of their loyalty to the organization was rated at a high level. This aspect of performance included, sorted in a descending order, intending to continue to work for the organization even though it requires hard work and high responsibility $(\bar{x}=4.23)$, expecting to continue to work for the organization until being retired $(\bar{x}=3.93)$, being willing and dedicated to work for the organization $(\bar{x}=3.82)$, and intending to work for the organization even in a crisis situation $(\bar{x}=3.78)$.

(6) The overall performance of the employees in terms of their willingness for cooperation was rated at a high level. This aspect of performance included, sorted in a descending order, being able to do the responsible duties completely and in time $(\bar{x}=$ 3.79 ), being willing to complete the assigned tasks even though there are many tasks to do $(\bar{x}=3.66)$, being able to complete the assigned tasks according to the requirement $(\bar{x}=3.66)$, and being able to complete the duties according to the job details specified in the job description $(\bar{x}=3.53)$.

(7) The overall performance of the employees in terms of the efficiency in work performance was rated at a high level. This aspect of performance included, sorted in a descending order, being dedicated to use creative ideas that are beneficial for work $(\bar{x}=3.83)$, always trying to use new ideas to improve the efficiency in work performance $(\bar{x}=3.64)$, always trying to use new ways of working or techniques or tools to enhance the efficiency in work performance $(\bar{x}=3.39)$, encouraging other members of the organization to create new ideas $(\bar{x}=3.29)$.

(8) The result of hypothesis testing showed that the corporate culture had a direct influence on the performance of the employees of the eldercare service business, with coefficient value of .87 and statistical significance level of .05 .

\section{References}

Chasserio, S. \& Legault, M-J. (2009). Strategic human resources management is irrelevant when it comes to highly skilled professionals in the canadian new economy. International Journal of Human Resource Management. 20(5), 1113-1131.

Delle, E. (2013). To stay or not to stay: Can organizational culture provide the staying power? Evidence from the Ghanaian Banking Sector. Research on Humanities and Social Sciences. 3(19).

Gubman, L.E. (2003). The engaging leader: winning with today's free agent workforce. Chicago: Dearborn Trade.

Hameed, A. \& Waheed, A. (2011). Employee development and its affect on employee performance a conceptual framework. International Journal of Business and Social Science. 2(13), Special Issue - July, 2011.

House, R. J., Gupta, V., Hanges, P. J., Javidan, M. \& Dorfman, P. W. (2004). Culture, leadership, and organizations: The GLOBE study of 62 societies. Thousand Oaks: Sage. 
Markowitz, G. A. (2012). Faculty intent to stay and the perceived relationship with supervisor at a career-focused university. Dissertations. University of Miami.

Osarenkhoe, A. (2010). A coopetition strategy - a study of inter-firm dynamics between competition and cooperation. Business strategy series. 11(6), 343-362.

Riolli-Saltzman, L. \& Luthans, F. (2001). After the bubble burst: How small high-tech firms can keep in front of the wave. Academy of Management Executive. 15(3), 114-124.

Rutherford, B., Park, J. K. \& Han, S-L. (2011). Increasing job performance and decreasing salesperson propensity to leave: An examination of an asiansales force. Journal of Personal Selling \& Sales Management. XXXI, 2 (spring 2011), 171-183.

Sangmanee, W. (2011). Organization and organizing (3nd ed). Bangkok: Rabeangthong Printing.

Sanguanwongwan, W. (2003). Management and organizational behaviors. Bangkok: Se-Education.

Shahzad, F., Luqman, R. A., Khan, A. R. \& Shabbir, L. (2012). Impact of organizational culture on organizational performance: An overview. Interdisciplinary Journal of Contemporary Research in Business. January 2012. 3(9).

Thammasane, S. (2012). Model of service business management for older persons in Thailand. FEU Academic Review, 6(1), 88-99.

Zeytinoglu, I. U., Keser, A., Yılmaz, G., Inelmen, K., Ozsoy, A. \& Uygur, D. (2012). Security in a sea of insecurity: Job security and intention to stay among service sector employees in Turkey. The International Journal of Human Resource Management. 23(13), July 2012, 2809-2823. 